\title{
Una corografía ilustrada inédita: la Descripción de las Yslas Philipinas de la Real Academia de la Historia de Madrid
}

\author{
Patricio Hidalgo Nuchera \\ Dpto. de Historia Moderna. Facultad de Filosofía y Letras \\ Universidad Autónoma de Madrid
}

\begin{abstract}
Se analiza el manuscrito 9/5.248 de la Real Academia de la Historia, depositado en ella en 1802 por legado testamentario de su antiguo poseedor, Joaquín Traggia, quien lo adquirió en Filipinas tres décadas antes. Se trata de un compendio geográfico-históricoetnográfico de las citadas Islas a mediados de la centuria ilustrada. El análisis de la obra, anónima y sin fechar, nos permite datarla en 1746 y denunciar su plagio respecto a la introducción geográfica de la crónica del franciscano Juan Francisco de San Antonio; pero frente a ésta, el texto que presentamos se singulariza por la amplitud de noticias acerca del estado fiscal y militar del archipiélago. Tras hacer un breve repaso de los fines de las corografías dieciochescas y de sus medios para fomentar el desarrollo económico -las descripciones geográficas-, analizamos el manuscrito, fijándonos en su contexto histórico, contenido, estilo, fuentes y finalidades, destacando entre éstas últimas la de presentar a las Filipinas como la reencarnación de una nueva Roma.
\end{abstract}

\section{Atribución y datación}

El manuscrito que presentamos pertenece a la Real Academia de la Historia de Madrid y se encuentra depositado en la "Colección Traggia", signatura 9/5.248. Consta de 126 folios ó 252 páginas, con numeración original. El hecho de que esta descripción se encuentre manuscrita puede radicar en la política de sigilo practicada por el gobierno español. En efecto, ante el temor de que potencias extranjeras pudieran conocer la realidad de las posesiones americanas, se pensaba que una forma de protegerlas era prohibiendo la difusión y publicación de cualquier estudio geográfico detallado, máxime si contenía datos militares tan precisos como pormenoriza éste. Por esto no se podían imprimir libros sobre América si no era con especial licencia del Consejo de Indias. ${ }^{1}$

¿Cómo y cuándo fue a parar esta descripción a la Real Academia de la Historia?. La obra fue adquirida en Manila por el padre Joaquín Traggia, de Santo Domingo, en una fecha comprendida entre 1767 y 1772, años en

1 Tal prohibición en ley $1 .^{\mathrm{a}}$, título XXIV, libro I de la Recopilación de Leyes de Indias de 1680, que recoge sendas cédulas de Valladolid, 21 de septiembre 1556 y Toledo, 14 de agosto de 1560. 
los que residió en las Islas Filipinas. Según refiere él mismo en una anotación autógrafa al final de la descripción (folio 126), pasó a Manila en la primera de las fechas en compañía del recién nombrado arzobispo don Basilio Sancho de las Santas Justa y Rufina ${ }^{2}$ y regresó a la metrópoli en 1772 "por negocios del Concilio provincial de aquellas Islas". Miembro de la Real Academia de la Historia desde 1791, a su fallecimiento en 1802, y por disposición testamentaria, esta obra pasó, junto al resto de sus manuscritos y libros, a los fondos bibliográficos de dicha institución madrileña. ${ }^{3}$

La descripción es anónima y está sin fechar. En cuanto a lo primero, el nombre de su autor no aparece en todo el texto. La única pista la encontramos en el folio 27, cuando aquél escribe que "Al presente se halla governando dicho obispado el Ylustríssimo Señor Maestro Don Ysidoro de Arévalo, natural de esta tierra, de prendas amabilíssimas, como que lo comuniqué en el tiempo que estube con su Ylustríssima para transportarnos por tierra a esta ciudad [Manila] con el motivo de haver arribado al puerto de Naga el navío que nos condujo del puerto de Acapulco". En otras palabras, nuestro autor llegó a Manila por tierra desde Naga, a cuyo puerto arribó, por causas que ignoramos, el navío que lo transportaba desde Nueva España. En Naga o en la cercana ciudad de Nueva Cáceres debió conocer al obispo de esta diócesis, por entonces don Isidoro de Arévalo, de quien quedó gratamente impresionado. Como éste ocupó la silla episcopal de Camarines entre los años 1741 y 1751, nuestro autor debió llegar a Naga entre ambas fechas.

También ignoramos todo sobre su personalidad. ¿Fue un religioso o un civil?. El hecho de que plagie la obra del franciscano Juan Francisco de San Antonio puede hacer pensar que se trata de un clérigo; ${ }^{4}$ pero la información de tipo fiscal y militar que añade nos inclina a creer que se trata de un funcionario civil o militar, que a la hora de redactar plagió la mayor parte de la obra del franciscano citado. Pero sobre ello volveremos más adelante.

¿Cuándo fue escrita esta obra?. Por lo dicho anteriormente tuvo que ser, necesariamente, después del nombramiento de don Isidoro de Arévalo

2 Ocupó la sede arzobispal filipina entre 1766 y 1787.

3 Sobre Joaquín Traggia véase el apéndice.

4 ¿Acaso franciscano?. Sin embargo, ha resultado negativa la consulta de la obra de Gómez Platero, Eusebio (OFM): Catálogo biográfico de los religiosos franciscanos de la provincia de San Gregorio Magno de Filipinas, desde 1577 en que llegaron los primeros a Manila hasta los de nuestros días, formado por el P. Fr. [...], por mandado del M.R.P. Ministro Provincial de la misma Fr. Pedro Moya, Manila, Imprenta del Real Colegio de Santo Tomás, 1880. 
como obispo de Nueva Cáceres, hecho que sucedió en 1741.5 Aparte de esto, un análisis interno del texto nos ayudará a fecharlo con más precisión. Una primera referencia al respecto la encontramos al principio de la obra (ff. 7-7v): "Es verdad que al presente se hallan estas yslas muy deterioradas con los sucesos adversos del mar y sus raras contingencias y no menos con las presentes guerras que tienen años a el tráphico, y por esto esta Manila expuesta a mil contingencias adversas, y más con los acaesimientos repetidos que se an visto y experimentan lastimosamente". Se refiere el autor al quebranto económico que sufrieron las Filipinas al suspenderse la navegación del galeón tras su apresamiento el 30 de junio de 1743 por George Anson.

Un dato más preciso lo encontramos en el folio 32. Al hablar del obispo de la Nueva Segovia — capital de la provincia de Cagayán, en la isla de Luzón-, el autor informa que es don Juan de Arechederra, por entonces "Gobernador y Capitán General de las Yslas por muerte de Don Gaspar de la Torre". Si Arechederra ocupó el gobierno entre 1745 y 1750, esta obra debió ser escrita entre dichos años. ¿Cuál?. La solución la encontramos en el folio 102: hablando de la comisaría de la Santa Inquisición, el autor nos informa que el citado Arechederra la ejerció "hasta 21 de septiembre del año pasado de 745 ", fecha en que cesó por su ascenso al gobierno de las islas. Por tanto, esta obra fue escrita en 1746.

\section{Una obra plagiada}

El hecho de ser la presente una obra de mediados del siglo XVIII nos llevó a compararla con la de su coetáneo Juan Francisco de San Antonio, miembro de la provincia franciscana de San Gregorio de Filipinas, ${ }^{6}$ pudiendo comprobar que la primera sigue en gran parte a la segunda. Para ello hemos cotejado ambas descripciones, llegando a los siguientes resultados.

5 Arévalo fue nombrado en 1741 y llegó a Nueva Cáceres al año siguiente. Fue consagrado en Cantón en 1744. Véase Abella, Domingo: Bikol Annals. A Collection of Vignettes of Philippine History, tomo I: The See of Nueva Cáceres, Manila, 1954, pág. 100. A Arévalo le sucedió el franciscano fray Manuel Matos.

6 Chrónicas de la apostólica provincia de San Gregorio de religiosos descalzos de N.S.P. San Francisco en las Islas Philipinas, China, Japón, etc. Parte Primera, en que se incluye la descripción de estas Islas, Manila, Imprenta del uso de la propia Provincia, sita en el Convento de Nuestra Señora de Loreto del Pueblo de Sampaloc, extramuros de la ciudad de Manila, por Fray Juan del Sotillo, 1738 y 1741 . 
Ambas comienzan con una descripción de la naturaleza de Filipinas. En la de San Antonio ocupa sus 13 primeros capítulos. Pues bien, la anónima no los transcribe por completo, sino que comienza a mediados de su capítulo V, exactamente en el f. 17; faltan, por tanto, los capítulos I a IV, la primera parte del V y los XI y XII de la obra del franciscano.

A continuación ambas obras describen topográficamente las islas y provincias de Filipinas. La de San Antonio abarca los capítulos XIV a XXXVII. Si bien ambas descripciones son similares, la anónima se singulariza en lo siguiente:

1. Especifica el número de pueblos de cada provincia; los tributos de la corona, lo que rentan y en qué productos; las cargas económicas de cada provincia y el saldo de sus respectivas cajas reales. Hay, pues, un interés fiscal que falta en la obra del franciscano.

2. ${ }^{\circ}$ La anónima recopila en la descripción de las provincias noticias que en la de San Antonio están dispersas por varios capítulos. Así por ejemplo:

- al hablar de la provincia de Camarines, la anónima reúne las noticias que San Antonio ofrece en sus capítulos XIX y LIV (salvo el catálogo de obispos de la diócesis, que la anónima omite);

- al describir la provincia de Cagayán, la anónima reúne las noticias que San Antonio ofrece en sus capítulos XXI y LVII;

- al tratar de la provincia de Cebú, la anónima recopila las noticias que San Antonio da en sus capítulos XXXIII, parte del LI y LIII, omitiendo el LII;

- al hablar de la jurisdicción de Cavite, la anónima reúne la información de los capítulos XXX y XXXVIII.

3..$^{\circ}$ El tercer punto en que se singulariza la relación anónima es que ésta hace referencia a personajes posteriores a la fecha de redacción de la descripción de San Antonio. Así:

- si éste anota como último obispo de Nueva Cáceres a Felipe de Molina y Figueroa, fallecido en 1738, la anónima cita como obispo de esta diócesis en aquel momento a Isidoro de Arévalo, nombrado en $1741 ;$

- si San Antonio cita como último obispo de Cebú a Manuel Antonio de Osio y Ocampo, fallecido el 9 de septiembre de 1737, la anónima 
cita como último obispo de dicha diócesis a Protasio Cavezas, nombrado el 7 de diciembre de $1741 ;{ }^{7}$

- por último, la anónima cita como obispo de Cagayán a Juan de Arechederra, nombrado el 2 de octubre de $1745,{ }^{8}$ dato que obviamente omite San Antonio.

La tercera parte de ambas obras está dedicada a la relación de las plazas, castillos, fuerzas y presidios existentes en toda la gobernación filipina. Aquí también la relación anónima sigue a la de San Antonio, aunque se singulariza en tres puntos:

1. La anónima tabula las cifras de artillería y pertrechos militares, hecho que falta en la de San Antonio. Ello nos indica que falta en ésta un claro interés militar que sí existe en la anónima.

2. ${ }^{\circ}$ Como ocurrió anteriormente, la relación anónima recopila información que en la de San Antonio está dispersa. Así, al hablar de Manila, la anónima recoge lo que en San Antonio está en los capítulos XXXVIII, LXVI, LXVII, LXI, LXIII, LXIV y LXV, omitiendo todo el capítulo LXII.

3. Al describir las reales providencias en beneficio de las fortalezas existentes en las islas, la anónima ofrece una información inédita en San Antonio al individualizar las plazas existentes en la real polvorista y la real fundición, con sus respectivos salarios.

El orden de las dos siguientes partes está invertido en las descripciones de San Antonio y la anónima. Si en la primera la parte cuarta está dedicada al origen y costumbres de los nativos de las islas y la quinta al estado eclesiástico, en la anónima es al contrario. Fijándonos en esta última, su parte cuarta ("Estado eclesiástico") corresponde a los capítulos XLVI, XLVIII, XLIX y L de la de San Antonio, omitiendo los XLVII, LVIII, LIX y LX; por otra parte, los capítulos LI a LVII no es que se omitan, sino que su información — correspondiente a los obispados sufragáneos de Cebú, Camarines y Cagayán - fue incorporada a la descripción de sus respectivas provincias.

7 Buzeta, Manuel y Bravo, Felipe: Diccionario geográfico, estadístico, histórico de las Islas Filipinas, Madrid, Imprenta de D. José C. de la Peña, 1851. 2 vol. Véase vol. I, pág. 545. A Cavezas le sucedió Miguel Lino de Ezpeleta en 1756.

8 García González, Antonio F.: El gobierno en Filipinas del Ilmo. Sr. Don Fray Juan de Arechederra y Tovar, obispo de la Nueva Segovia, Granada, 1976, pág. 33. 
La quinta y última parte de la descripción anónima está dedicada al origen y costumbres de los indios de Filipinas. Transcribe por completo el capítulo XXXIX de San Antonio y pequeñas partes de XLI y XLII; pero omite el XL, XLIII, XLIV y XLV.

Este plagio casi completo no nos ha de extrañar, ya que una de las características de la historiografía de la época es su falta de originalidad; 9 a diferencia de hoy los plagios eran habituales y en muy pocas ocasiones se citaban las fuentes de información. Sin embargo, la presente descripción se singulariza en su amplitud de noticias acerca del estado fiscal y militar de las islas, lo que nos lleva a pensar que fue encargada en un tiempo y con una finalidad muy determinados.

Esta falta de originalidad nos indica que ésta no es la primera descripción que se realizó sobre las Filipinas. En efecto, desde su descubrimiento diversos autores describieron su geografía, su naturaleza y los avatares de la colonización. En su mayor parte fueron religiosos, hecho que se debe a ser ellos una parte importante de los hombres cultos de la época y a estar encargados de escribir las historias locales de sus respectivas órdenes. Todos - también nuestro anónimo autor-mezclan en sus obras noticias históricas, geográficas, etnográficas, artísticas, etcétera. Casi siempre la descripción geográfica encabeza la obra, como preámbulo que ayuda a situar al lector en el marco donde se desarrolla la acción evangelizadora; pero para evangelizar a los nativos era necesario antes conocerlos; de ahí el interés por sus costumbres y su historia prehispánica. Pues bien, este compendio geográfico-histórico-etnográfico de una región conforma el género corográfico tan en boga en el siglo XVIII, al cual pertenece la descripción que aquí presentamos.

\section{Las corografías dieciochescas}

Si acudimos al Diccionario de la Real Academia Española, la corografía es definida como "descripción de un país o de una región". Para diferenciarla de la "topografía", los autores de los siglos XVIII y XIX aplicaban a la primera la precisión de ser una descripción de una provincia,

9 El propio San Antonio, en el capítulo I de su obra (ff. 2-3) justifica el plagio: " $Y$ con esto sigo el tan practicado rumbo, sin que tengan los otros escritores por agravio el repetir de otro modo lo mismo que nos dejaron escrito; pues además de pedirles (como les pido) la venia a todos, es útil (en pluma del grande Agustín) escribir con diverso estylo las mismas questiones escritores varios en multiplicados libros, para que una misma vianda se haga sazonada al gusto de todos, según la variedad del guisado con que se ofrece a cada uno... Además que no todos los lectores tienen una librería llena de todos los libros para recurrir a ellos en lo que les omita el mío..." 
mientras reservaban la segunda para la descripción más concreta de un lugar particular, como pueblo, villa, etcétera. ${ }^{10}$

Uno de esos autores dieciochescos fue el jesuita almeriense Pedro Murillo Velarde (1696-1753). ${ }^{11}$ En el Libro I de su Geographía Histórica diferenciaba los términos cosmografía, geografía, corografía y topografía. Textualmente refiere que:

"la Cosmografía es la descripción del Mundo o del Universo, en que se comprende cielo y tierra. La Geografía es descripción de la Tierra, en que se comprende la tierra y el agua, que todo junto se llama globo terráqueo; globo por su figura esférica o redonda, y terráqueo por incluir la tierra y el mar. La Corografía es descripción de un Reino, de una Provincia o de una región particular. Topografía es descripción de una ciudad, de una plaza, de una villa, de un campo o de un paraje o sitio particular, en

10 Ver la introducción de López Ontiveros, Antonio, a la Corografía histórico-estadística de la provincia y obispado de Córdoba. Por el licenciado D. Luis María Ramírez y de las Casas-Deza. Córdoba, 1986. 2 v.; vol. I, pág. XCIX. Este autor remonta el origen de las corografías al mundo griego, donde los geógrafos interesados por las realidades físicas, humanas y económicas protestan por la reducción de su disciplina a la descripción geométrica y astronómica de la superficie terrestre y desarrollan, junto a la "Geografía" fundada sobre la astronomía, la geometría y la física "teórica", una disciplina "descriptiva", que reposa sobre la observación y la exploración, que recibe el nombre de "Corografía". Esta geografía descriptiva, practicada por Polibio, Estrabón y otros no será destronada hasta la implantación de la "Moderna geografía" en la segunda mitad del siglo XIX, preconizadora de una exposición causal, sistemática y en suma científica.

11 De entre sus varias obras es necesario destacar dos referentes a las islas Filipinas, donde estuvo destinado desde 1723 a 1750: la Historia de la Provincia de Philipinas de la Compañía de Jesús. Segunda parte, que comprehende los progresos de esta Provincia desde el año de 1616 hasta el de 1716, Manila, en la Imprenta de la Compañía de Jesús, por D. Nicolás de la Cruz Bagay, año de 1749. Esta obra es la continuación - la "segunda parte" a que hace referencia el título— de la de su hermano de orden Francisco Colín, quien a su vez continuó la de Pedro Chirino. Su otra obra es la Carta Hidrográphica y Corográphica de las Islas Philipinas, dedicada al Rey Nuestro Señor por el Brigadier Don Fernando Valdés Tamón, Caballero de la Orden de Santiago, Gobernador y Capitán General de dichas Islas (Manila, 1734). Pero su obra cumbre, editada a su regreso a España, es la monumental Geographía Histórica donde se describen los Reinos, Provincias, Ciudades, Fortalezas, Mares, Montes, Ensenadas, Cabos, Ríos y Puertos, con la mayor exactitud, y se refieren las Guerras, las Batallas, las Paces y Sucesos Memorables, los Frutos, las Riquezas, los Animales, los Comercios, las Conquistas, la Religión, los Concilios, las Sectas, los Gobiernos, las Lenguas, las Naciones, su genio y su carácter, y se hace una Compendiosa Memoria de los Varones insignes en Virtud, Letras, Armas y Empleos de cada Reino; lo que da luz para la inteligencia de la Sagrada Escritura, de la Historia Antigua y Moderna, Sacra, Eclesiástica, Civil y Natural, y de las Fábulas y los Poetas. La escribía el P. Pedro Murillo Velarde, de la Compañía de Jesús. Y la dedica a la Sacratísima Virgen de Guadalupe que se venera en México. Con privilegio, en Madrid, en la Oficina de D. Gabriel Ramírez, Criado de la Reina Viuda N. Señora, Calle de Atocha, frente de la Trinidad Calzada. Año de 1752. 10 v., de los cuales parte del VIII se dedica a las Islas Filipinas y el IX a América.

Sobre la figura de Murillo Velarde, véase el estudio preliminar de Serrera Contreras, Ramón María, a la edición facsímil del citado tomo IX, realizada — bajo el título de Geographía de América (1752) — en Granada, 1990; y la introducción del citado y de María Angeles Gálvez a la publicación de la parte de Andalucía, correspondiente a los capítulos XII, XIII y XIV del Libro I, realizada — bajo el título de Geographía de Andalucía (1752)— en Sevilla, 1988. 
que se pintan los ríos, montes, edificios, castillos, palacios, plazas, árboles y prados. La Hidrografía es descripción de las aguas, mares, lagos o ríos". ${ }^{12}$

A decir verdad las corografías dieciochescas no se limitan a describir los accidentes geográficos de un país (situación, emplazamiento, límites, producciones), sino que abarcan aspectos tales como la historia, la población, hombres célebres, monumentos, etcétera. Puede decirse que la corografía es una síntesis lograda de historia, geografía y arte. Creemos que ello explica el porqué Murillo Velarde, al redactar su Geographía, a la que define como "una ciencia físico-matemática que enseña la descripción universal de toda la tierra", la acompañó del calificativo de Histórica, aunque diese prioridad al primero de los términos:

"Este título contiene dos asuntos: uno principal, otro accesorio; uno en recto, otro en oblicuo. La Geografía es el principal, la Historia el accesorio, pero ambos de suma extensión: el uno comprende toda la redondez del globo terráqueo; el otro el curso de todos los siglos". ${ }^{13}$

Y, en este sentido, Serrera Contreras ${ }^{14}$ opina que la obra del jesuita almeriense está concebida más como una suma de "corografías" que como una geografía explicativa concebida desde unos claros criterios territoriales o administrativos.

¿A qué aspiran las corografías dieciochescas?. Evidentemente no se quedan en la mera descripción geográfica de datos relativos a situación, población y producciones, sino que aspiran, en la línea ilustrada del momento, a preconizar una serie de medidas económicas que fomenten el desarrollo económico. En este sentido estamos de acuerdo con Muñoz Pérez en su hipótesis de la aparición de una conciencia de diferenciación regional española en el siglo XVIII y su correlato de que los distintos problemas reclamaban no una ley general, sino una serie de medidas particulares de fomento y desarrollo para cuya adopción debía tenerse en cuenta la realidad geográfica y, esencialmente, la de carácter regional. Vemos, pues, cómo la geografía como ciencia estuvo al servicio del intento de reestructuración del imperio español del siglo XVIII. ${ }^{15}$ Pero para poder acometer dicha reestructuración hacía falta una mayor información de las realidades a transformar.

12 Murillo Velarde, Geographía Histórica, Libro I ("De la Geographía en general y en particular"), capítulo 1. ("Qué es Geographía?"), págs. 1 y 2.

13 Geografía Histórica, "Prólogo al lector y razón de la obra", pág. 1.

14 Estudio preliminar citado, pág. XXXII.

15 Muñoz Pérez, José: "Papel de la Geografía en el programa español de reajuste económico del XVIII español”. Estudios Geográficos 67-68, Madrid, 1957, págs. 403-427. 


\section{La información sobre las Indias}

Para conseguir esta información el Consejo de Indias tenía dos alternativas: crear un cuerpo permanente de especialistas que recorriesen los dilatados espacios hispanoamericanos; o contar con la colaboración de las propias autoridades indianas, facilitándoles una normativa para que todos los informes fueran uniformes. El Consejo de Indias prefirió esta segunda vía.

En un principio, se encargó a todos los navegantes y descubridores el envío de descripciones e informes de las tierras que descubrían y conquistaban. Más tarde, el presidente del Consejo de Indias, Juan de Ovando, ordenó la formación de un libro descriptivo de todas las provincias indianas, a realizar por el cosmógrafo y cronista mayor de las Indias. ${ }^{16}$ Para llevar a cabo su tarea, se enviarían a Indias unos cuestionarios muy completos realizados por el propio Consejo; las respuestas de las autoridades locales a dichos cuestionarios se conocen con el nombre impropio de Relaciones Geográficas. ${ }^{17}$

La tarea de organizar las Indias hizo que el recurso a este sistema de preguntas generalizadas fuera frecuente en el siglo XVI. Lo fue menos en el XVII, siglo en el que únicamente se enviaron tres cuestionarios genera-

16 Véanse las ordenanzas para la formación del libro de las descripciones de Indias, San Lorenzo de El Escorial, 3 de julio de 1573. Transcritas en Solano, Francisco de (ed.): Cuestionarios para la formación de las Relaciones Geográficas de Indias. Siglos XVI-XIX. Madrid, 1988, págs. 16-74.

17 Relación geográfica es denominación del siglo XIX. Según Solano, (Cuestionarios..., pág. XVII), anteriormente a estas informaciones se les calificó como descripciones geográficas, descripciones de la tierra o incluso relaciones topográficas. Aún más, para Ponce Leiva, Pilar (véase su estudio introductorio a las Relaciones histórico-geográficas de la Audiencia de Quito. Siglos XVI-XIX, Madrid, 1991, tomo I, pág. XXI), el término geográfico tiene escaso fundamento, ya que "ni por la temática de los cuestionarios a los que responden, ni por la intencionalidad con que fueron enviados pueden considerarse como textos única o esencialmente geográficos”. ¿Por qué, entonces, se les denominó así?. La misma autora (ibidem, pág. XXII) aventura tres causas: porque la publicación de las primeras relaciones fueron amparadas por la Sociedad Geográfica de Madrid; porque la primeras publicadas a partir de 1881 pertenecen al siglo XVI, momento en que lo importante era conocer lo descubierto; y porque la mayor parte de las relaciones del siglo XVI respondían al cuestionario de 1577 , tal vez el más geográfico de cuantos se enviaran. Por otra parte, enfatizar el carácter geográfico de las relaciones conlleva el peligro de relegar aquellos informes relativos a oficios públicos, cuentas de la Real Hacienda, indios tributarios, etc. que, sin tener una temática geográfica, surgen por orden directa de algunos cuestionarios. Para superar esta limitación y poder considerar un texto como Relación geográfica, Ponce Leiva (ibidem, pág. XXIV) propone el criterio de que aquél responda bien a un cuestionario previo, bien que sea consecuencia de una orden explícita del gobierno superior. En ambos casos es posible que únicamente nos encontremos con respuestas parciales a lo pedido; ello se debe a que, si los cuestionarios eran extensos, se parcelaban en varias materias (geografía, población, tributos, hacienda, defensa, etc.) y se enviaban a distintas personas. Pues bien, estas respuestas parciales, que muchas veces no hacen mención al cuestionario u orden global de que proceden, también hay que considerarlas como Relaciones geográficas. 
les a América $\left(1604,1635\right.$ y 1648).$^{18}$ Para Ponce Leiva la causa estriba en la crítica que desde principios de dicho siglo se hizo al propio sistema de cuestionarios, ya que las respuestas al de 1604 "fueron, en general, tardías y de dudosa calidad", abriéndose paso la desconfianza "entre quienes tenían a su cargo la tarea de sistematizar y hacer operativa la información recibida". ${ }^{19}$ Como alternativa al desprestigiado "cuestionario", el Estado recurrió a otros instrumentos de información, como fueron el envío de órdenes precisas relativas a cuestiones específicas, a visitas generales de los distintos territorios y al envío de expediciones científicas.

En el siglo XVIII se va a potenciar el afán de conocimiento de la realidad geográfica indiana, cuya raíz hay que buscarla en el deseo de la nueva dinastía borbónica de revitalizar la decaída metrópoli hispana. La solución estribaba en conseguir que los territorios americanos bombearan crecientes cantidades de recursos, para lo cual era necesario aprovecharlos más racionalmente. Con este fin, y con el paralelo de disminuir la autonomía política que las Indias habían conseguido durante la época de los Austrias, se reformó la administración colonial, se enviaron funcionarios más eficaces, se agilizó el sistema comercial, se rompió el monopolio mercantil gaditano, se favoreció la producción de aquellas materias primas requeridas por las industrias metropolitanas... Ya señalamos anteriormente que ahora se toma conciencia de que la diversidad de los territorios americanos necesitan no una ley general, sino medidas particulares que coadyuven a su desarrollo. Pues bien, de aquí nace la necesidad de tener una información actualizada acerca de las diversas realidades americanas.

Con esta intención, el 30 de agosto de 1739 se envió al gobernador de Filipinas, don Gaspar de la Torre, una orden orientada a informar sobre la realidad del archipiélago. ${ }^{20}$ Podemos considerarla un precedente de la cédu-

18 A destacar que en 1679 se ordenaba a las autoridades eclesiásticas indianas el envío de datos individualizados de todas las ciudades, villas y poblaciones que hubiese en las respectivas jurisdicciones de sus obispados, así como de la población española e india. Pero ante la queja del obispo de Santiago de Guatemala de no tener los medios necesarios para llevar a cabo dicha labor, dos años después el rey la encargó a las autoridades civiles. Véanse las reales cédulas de 21 de abril de 1679 y 5 de agosto de 1681, publicadas en Muro Orejón, Antonio: Cedulario americano del siglo XVIII, Sevilla, 1956, tomo I, docs. 4 y 89.

19 Ponce Leiva, Relaciones histórico-geográficas..., T. I, págs. XXXVIII-XXXIX.

20 AGI. Filipinas 450. Carta de don José de la Quintana al gobernador de Filipinas, Madrid, 30 de agosto de 1739. La orden dió lugar a un voluminoso expediente, acabado en julio de 1746, que podemos considerar como una relación geográfica. Citada por Serrera Contreras en su estudio preliminar a la obra de Villaseñor y Sánchez, José Antonio de: Suplemento al Theatro Americano. La ciudad de México en 1755, México, 1980, pág. 49, nota 117. 
la de 19 de julio de 1741 firmada por Felipe V en el Buen Retiro. Dirigida a los virreyes de Nueva España, Perú y Nueva Granada y a todos los presidentes de Audiencias, gobernadores y capitanes generales de las provincias americanas, ordenaba el acopio y envío de noticias con el fin de "instruir" con ellas la descripción del estado de las provincias. ${ }^{21}$ Pero las órdenes fueron llevadas a cabo únicamente en el virreinato de Nueva España.

En efecto, en 1743 el conde de Fuenclara, don Pedro Cebrián, comisionaba al cronista de la ciudad de México, el sacerdote don Juan Francisco Sahagún de Arévalo Ladrón de Guevara, y al contador de reales azogues don José Antonio de Villaseñor y Sánchez, para que se encargaran de la tarea de formar cuestionarios que resumieran los intereses estatales, así como reunir los informes que remitiesen los gobernadores, alcaldes mayores y justicias de todos los distritos del virreinato, dándoles forma, "sacando de ellos un extracto comprehensivo de todo cuanto dichas justicias informaren". En otras palabras, se les pedía que resumieran los datos reunidos de las respuestas a su cuestionario. ${ }^{22}$

Sahagún y Villaseñor elaboraron el cuestionario al que debían ajustarse las autoridades locales en sus respuestas. Comenzó a repartírseles el 6 de marzo de 1743: cada una de ellas recibiría un despacho del virrey que reproducía la cédula de 1741, con la formación de la comisión y las órdenes sobre los procedimientos a seguir. ${ }^{23} \mathrm{El}$ mencionado cuestionario constaba de ocho preguntas en las que se inquiría noticias sobre los pueblos, sus habitantes, clima, distancia entre asentamientos, situación económica, producción y comercio, estado de las misiones....

Con los datos reunidos, la comisión Sahagún-Villaseñor debía realizar una síntesis homogénea del estado del virreinato. Por renuncia del primero, la tarea recayó exclusivamente sobre Villaseñor, siendo su resultado impreso en México en 1746 (la primera parte) y en 1748 (la segunda) bajo el nombre de Theatro Americano. Descripción general de los reinos y provincias de la Nueva España. ${ }^{24}$

21 AGI. Indiferente General 107, ff. 103-103v. Publicada en Solano, Cuestionarios..., doc. 19, n. ${ }^{\circ}$, págs. 141-142.

22 Auto del virrey de Nueva España conformando una comisión que organice un cuestionario que facilite la recogida de datos solicitados. México, 4 de enero de 1743. Publicado en Solano, Cuestionarios..., doc. 19, n. ${ }^{\circ}$ 3, págs. 142-143.

23 Un ejemplo de dicho despacho con el cuestionario al que debían ajustar sus respuestas, en Solano, Cuestionarios..., doc. 19, n. ${ }^{\circ}$ 3, págs. 143-144.

24 Existió un Suplemento al Theatro Americano. La ciudad de México en 1755, no publicado en vida del autor. Lo fue en 1980 por la Universidad Nacional Autónoma de México con estudio preliminar de Serrera Contreras. 
A pesar de su impresión, la obra de Villaseñor tardó en distribuirse. En realidad el hecho de que se imprimiera fue algo excepcional, pues las relaciones geográficas no se encargaban con el fin de destinarlas al público en general, ya que contenían noticias que podrían ser utilizadas por naciones extranjeras para el contrabando o, incluso, la ocupación. Además, es evidente que un libro impreso era de más fácil manejo y podría llegar a un mayor número de personas. Por estas razones en 1750 se determinó prohibir la venta, donación y difusión pública del Theatro Americano. ${ }^{25}$

\section{Análisis de la Descripción de las Yslas Philipinas}

\section{Contexto histórico}

Para la mejor comprensión del texto, creo necesario comenzar este apartado reseñando la situación de las islas en los años en que fue escrito. Desde mediados de la tercera década del siglo XVIII las relaciones entre España y Gran Bretaña se fueron deteriorando. La causa era la negativa de la South Sea Company a pagar la deuda de 68000 libras esterlinas contraída con la corona española. En caso de no liquidarse, Felipe V amenazó con rescindir el asiento de negros. Pero lejos de asustarse, los comerciantes ingleses recogieron el desafío y, comprendiendo que la guerra estaba en sus manos, negaron el pago de una sola libra esterlina. El episodio de la Oreja de Jenkins ${ }^{26}$ será una mera excusa.

El 3 de octubre de 1739 José de la Quintana, secretario del Despacho Universal de Marina e Indias, comunicaba al gobernador Gaspar de la Torre cuál era la situación de las relaciones con Gran Bretaña, participándole que eran conflictivas y podían influir en Filipinas. Por indicación de la corona, de la Torre debía cuidar de los siguientes puntos: evitar el comercio de los ingleses en Filipinas y requisar cuantos efectos suyos se hallasen en las islas; estar preparados para resistir cualquier posible ataque y prevenir que el galeón navegase con las seguridades oportunas. ${ }^{27}$

25 AGI. México 570. Real Cédula. San Lorenzo de El Escorial, 7 de octubre de 1750.

26 Se refiere a la tempestuosa sesión de la Cámara de los Comunes inglesa en la que dicho capitán se presentó exhibiendo la oreja que le habían cortado los españoles cuando realizaba contrabando en el Caribe. Fue la excusa para declarar la guerra, que se denominó por ello guerra de la oreja de Jenkins.

27 AGI. Filipinas 384. Don José de la Quintana a don Gaspar de la Torre. Madrid, 3 de octubre de 1739 . 
La guerra se declaraba el 3 de noviembre de 1739, enlazando al año siguiente con la de la Sucesión de Austria, con lo que se va a prolongar hasta 1748. Uno de los objetivos ingleses era Manila. Sin embargo, la toma por parte de Francia (aliada de España con la firma del segundo Pacto de Familia de 1743) de Madrás hizo que la armada inglesa desviara su objetivo a la recuperación de su factoría. Pese a todo, Lord Anson logró apresar el patache Covadonga, que volvía de Acapulco con el real situado y el producto de las ventas del permiso de los comerciantes manileños.

En Filipinas la guerra ocasionó la suspensión de la carrera de Acapulco, la toma de medidas para proteger Manila y Cavite y el aviso a los alcaldes mayores de las provincias del archipiélago para que informasen, si lo hubiese, de cualquier movimiento de la armada enemiga en las islas. Esta vez no ocurrió nada y la paz se firmó en 1748; más tarde, en la posterior Guerra de los Siete Años, Manila caería en manos inglesas el 24 de septiembre de $1762 .{ }^{28}$

Como señalábamos con anterioridad —nota 20-, el 30 de agosto de 1739 se solicitaba al gobernador de Filipinas, Gaspar de la Torre, que informase de la realidad del archipiélago, siendo una de sus finalidades la de conocer las defensas de las islas en esta crítica época. Curiosamente, el informe que presentamos contiene amplias noticias sobre la situación y estado de las diferentes fortalezas militares. Pero el texto va más allá, ofreciéndonos una valiosa información de las islas a mediados de la centuria ilustrada.

\section{Contenido de la obra}

En cuanto al contenido de la obra en sí, está dividido en cinco partes, lo que facilita su utilización. La primera está dedicada al mundo natural, ofreciéndonos una información acerca de la fertilidad de las islas, sus riquezas, frutos, plantas y árboles "fructíferos", maderas, peces y animales. La segunda parte ofrece una información básicamente de tipo geográfico. Después de describir las islas Marianas, el autor se centra en el resto de las

28 Para la situación de las Filipinas en esta época, véanse las obras de Rodríguez García, Vicente: El gobierno de Don Gaspar Antonio de la Torre y Ayala en las Islas Filipinas, Granada, 1976, principalmente págs. 159 y siguientes y García González: El gobierno en Filipinas del Ilmo. Sr. Don Fray Juan de Arechederra y Tovar, obispo de la Nueva Segovia, Granada, 1976, principalmente págs. 17-22. 
provincias en que se dividía la gobernación de las Filipinas. En todas las descripciones el autor sigue un esquema parecido: límites de la jurisdicción, distancias geográficas, frutos de la tierra, número de pueblos, los tributos que pertenecen a la corona, lo que producen anualmente y lo que, descontadas las cargas y gastos usuales, se ingresa en las cajas reales de Manila.

La información contenida en la tercera parte es básicamente de tipo militar. Sorprende la cantidad de fuerzas militares, muy superior a la existente en otras regiones de las Indias. La causa de ello hay que ponerla en relación con la existencia de una doble frontera en el territorio de las islas Filipinas: una exterior, frente a los musulmanes del sur, principalmente de Mindanao y Joló; y otra interior, frente a pueblos indígenas refractarios a la penetración española. Con buen criterio expositivo, el anónimo autor escalona su información en tres niveles: el primero se centra en la capital, Manila. Tras una descripción de su trama urbana y de sus instituciones principales (comercio, gobernador, audiencia y contaduría), nos ofrece noticias acerca de las fortificaciones que la defienden, la fuerza de Santiago y la de San Felipe de Cavite. A continuación, nos informa acerca de las veintidós fortalezas y presidios desperdigados por las distintas jurisdicciones de las islas, dando una relación de su artillería, pertrechos, gente de mar y sueldos. Por último, nos ofrece una relación de las distintas providencias dadas tanto por la corona como por el gobierno de las islas, en orden a mantener las referidas fortalezas.

La cuarta parte de la obra trata del gobierno espiritual de los habitantes de las Filipinas. En este sentido nos informa acerca de la llegada de los primeros religiosos, la erección de la catedral, los estipendios de su cabildo catedralicio, la jurisdicción del arzobispado, la comisaría de la Santa Inquisición, el tribunal de la Santa Cruzada, las iglesias y colegios de Manila y, por último, de los curatos de religiosos existentes en las islas.

Cierra la descripción una relación sobre el origen de los indios que las habitan. El autor reduce a tres los tipos de gentes que los españoles encontraron cuando llegaron allí en 1565 (f. 118): "La primera, los que dominavan gobernando como señores absolutos, políticos en su modo. La segunda, de negros montaraces y bárbaros, que en lo alto de los montes habitaban como brutos. La tercera, de hombres ni tan bárbaros ni tan políticos como los passados, pues aunque vivían retirados no aborrecían la política y comercio". 


\section{Estilo}

En cuanto al estilo, al estar basada en la descripción de Juan Francisco de San Antonio hace que la que aquí presentamos tenga la sequedad propia de quien no ha tenido vivencias personales en los lugares que describe. Al copiar, nuestro anónimo autor no aporta datos personales de si intervino en algún suceso, no hay admiración por edificio alguno con pasión, no se realizan fieles descripciones de los pueblos o paisajes. Si acaso, al describir el obispado de Nueva Cáceres (capital de Camarines) se muestra más preciso: recordemos que nuestro autor arribó al puerto de Naga a su llegada desde Nueva España y que conoció al obispo don Isidoro de Arévalo, de quien refiere puntuales noticias. ${ }^{29}$ Pero, en general, no tienen cabida en esta descripción los recuerdos personales ni los detalles costumbristas típicos de quien ha recorrido personalmente el territorio que describe.

La situación cambia en el capítulo dedicado al origen de los indios filipinos, pero ello no es mérito de nuestro anónimo autor, sino del que plagia. En efecto, ahora la pluma de éste - San Antonio - se hace más libre, como si no tuviera que sujetarse a un guión preestablecido. No sólo informa de las hipótesis más al uso, sino que las contradice e incluso arriesga opiniones personales. Un ejemplo de ello lo tenemos cuando habla del tercero de los tipos indígenas a que hacíamos referencia anteriormente (f. 119): primero ofrece las hipótesis existentes, contradice después la de quienes creen que descendían de los negrillos o primitivos señores de las Filipinas porque "no se parecen en nada a aquéllos"; y por último, se inclina a pensar que son mestizos de malabares e indios por su "color moreno claro, nariz aguileña, ojos encendidos, pelo lacio, dócil genio y buen trato".

\section{Fuentes}

Escasas son las fuentes historiográficas mencionadas por nuestro anónimo autor. Como ya señalamos, ello es característico de la historiografía del momento, donde lo habitual era el plagio y el ocultamiento de las fuentes de información. Ya hemos mostrado cómo esta descripción está basada

29 Así - folio 27-, que fue secretario de los arzobispos de Manila Francisco de la Cuesta (nombrado el 28 de abril de 1704) y Carlos Bermúdez de Castro (que lo fue el 20 de noviembre de 1720); vicario general en sede vacante y después con el arzobispo Juan Angel Rodríguez (nombrado el 18 de diciembre de 1731). Estando en este cargo ascendió en 1742 al obispado de Nueva Cáceres. 
en la de fray Juan Francisco de San Antonio. ¿Cuáles son las fuentes de éste?. Él mismo nos las cita en el prólogo de su obra: los manuscritos de los cronistas que le precedieron en la tarea de redactar la historia de su orden franciscana, tales como fray Marcelo de Ribadeneira, fray Antonio de Llave o de Padua, fray Francisco de Santa Inés, fray Manuel Bautista de Puga, fray Domingo de San Lorenzo, fray Domingo Martínez y fray Sebastián de Totanés; además de ellos, tuvo a la vista otros muchos opúsculos — manuscritos e impresos — de antiguos religiosos. Aunque nuestro copista anónimo no anota todas las fuentes que cita San Antonio, sí nos señala algunas, tales como la Chrónica General de los Padres Agustinos Descalzos (f. 53v); el portugués Joao de $\operatorname{Barros}^{30}$ (f. 124v); y los padres Francisco Combés ${ }^{31}$ y Francisco Colín, ${ }^{32}$ ambos jesuitas. Combés es citado en tres ocasiones, siempre en relación con la isla de Mindanao (ff. 53v, 57 y 123); Colín en dos, una en relación al perímetro de Mindanao (f. 53v) y otra con respecto a los indios que habitaban en Cagayán e Ylocos, provincias situadas al norte de la isla de Luzón (f. 124). Con relación a este último, San Antonio - y por tanto su copista - toman distancias, pues ponen

30 Vivió entre 1496 y 1570 . Su obra más importante se titula Decadas da India, en total cuatro: Primeira Decada: Asia de Joam de Barros, dos fectos que os Portuguezes fizeram no descobrimento e conquista dos mares e terras do Oriente, Lisboa, 1552. Segunda Decada da Asia de Joam de Barros, dos fectos que os Portuguezes fizeram, etc., Lisboa, 1553. Terceira Decada da India de Joao de Barros, etc., Lisboa, 1563. Quarta Decada da Asia de Joao de Barros, dedicada a el-Rei D. Filippe II nosso senhor; reformada, accrescentada e illustrada com notas e taboas geographicas por Joao Baptista Lavanha, Madrid, 1615. Las Decadas I, II y III fueron reeditadas, por orden y a costa del Senado da Camara de Lisboa, en 1628, 3 tomos; a éstas se junta, para completar la colección, la Decada $I V$ de 1615 arriba mencionada. La Decada I fue reimpresa en Lisboa en 1752. Más tarde serán reimpresas todas las cuatro Decadas, también en Lisboa, los años de 1777-78, 8 tomos, a los que se unió un volumen conteniendo la Vida de Joao de Barros, por Manuel Severim de Faria, y un minucioso Indice geral de todas las Decadas. Ver Diego Barbosa, Bibliotheca Luisitana. Historica, Critica e Cronologica, Lisboa, 1747.

31 Es el autor de la Historia de Mindanao y Joló, Madrid, 1667. Reeditada por Wenceslao E. Retana, con la colaboración del padre Pablo Pastells, en Madrid, 1897. El padre Francisco Combés nació en Zaragoza el 5 de octubre de 1620. Ingresó en la orden jesuita y en 1643 se traslada a Manila, siendo al poco tiempo destinado a Zamboanga, en la isla de Mindanao. La obra fue escrita entre 1662 y 1664 con un tono panegírico con el fin de incidir en el ánimo del gobernador Manrique de Lara, quien acababa de decretar el abandono de las fortalezas del sur con el fin de reforzar las defensas de Manila, frente al esperado ataque del pirata chino Coseng. Combés falleció en la travesía hacia Acapulco el 29 de diciembre de 1665 cuando regresaba a España.

32 Nació en Ripoll el 15 de julio de 1592 y murió en el noviciado de San Pedro Macati el 6 de mayo de 1660. Su obra principal se titula Labor evangélica, ministerios apostólicos de los obreros de la Compañía de Jesús, fundación y progresos de su provincia en las Islas Filipinas. Parte Primera, sacada de los manuscritos del Padre Pedro Chirino, Madrid, 1663. Reeditada por Pablo Pastells, en Barcelona, 1900. 3 v. Todo su Libro I es una descripción geográfica (capítulos I-XVIII; págs. 1-113) e histórica (capítulos XIX-XXIV; págs. 114-166) de las Filipinas. 
en duda su afirmación de que los indios de tales provincias desciendan de japones o chinos por el hecho de "haberse hallado allí sepulturas de hombres de mayor estatura que los yndios y algunas alajas de Japón y China que se han conservado entre ellos" (f. 124). San Antonio y su copista no están muy seguros de este origen porque dichos indicios "pueden proceder de otros varios acaecimientos, con la gran cercanía de China y Japón... Pero siempre nos quedamos en congeturas como en todo después de tanto trabajo; sirva sólo de luz para que otros discurran más verdaderos principios..." (ff. 124-124v.). Por tanto, estamos en este caso - y no en otros, como veremos a continuación - ante unas personas típicas del siglo ilustrado, con una actitud científica que duda ante los criterios de autoridad.

\section{Finalidades de la Descripción: ¿referente geográfico, corografía dieciochesca o utopía renacentista?}

Si consideramos esta obra un mero informe geográfico, las finalidades de su autor debieron ser las mismas que movieron a San Antonio a realizar la suya. En este sentido, el franciscano nos las especifica en la capítulo I de su obra, titulado precisamente "De los motivos de este libro": servir para la perfecta "inteligencia" de los acontecimientos historiados; para que los lectores de la obra no tuvieran que recurrir a otros libros, que generalmente no poseían, para buscar noticias referentes al clima, alimentos, costumbres, etcétera, de las islas; y, sobre todo, para acabar con la ignorancia que se tenía en España sobre el archipiélago filipino, razón por la que muchos misioneros se retraían de ir allá. Asimismo, San Antonio piensa que su descripción corográfica servía (f. 4) para el pretérito ("porque por esta descripción se podrán regular bien las virtudes de los siervos de Dios que nos precedieron y se podrá entender la substancia de los sucesos entretexidos"), para el presente ("para remedio de la necesidad en que nos hallamos si llegassen a penetrar los Señores Ministros lo grande de la mies en tan corto número de obreros") y para el futuro ("porque en este mapa podrán abrir y explayar los ojos los religiosos que ayan de venir por misioneros, tanteando y compaseando en él su vocación por tan raros clymas y rumbos").

Sin embargo, ya hemos señalado que esta descripción se singulariza, con respecto a la de San Antonio, por sus noticias acerca del estado fiscal y militar de las Islas. ¿Respondería esta descripción a un encargo de las autoridades civiles filipinas?. ¿O, acaso — enlazando con el tema tratado de 
la información sobre el Nuevo Mundo- se trata de la respuesta a un encargo del gobierno metropolitano?. Recordemos que en 1739 para Filipinas y en 1741 para Nueva España se había ordenado llevar a cabo sendas descripciones geográficas. Las noticias referentes a la hacienda y a las fuerzas militares pueden avalarlo. Pero en su contra hallamos en ella lagunas tan importantes como una falta absoluta de datos sobre la población española, mientras que de la indígena sólo se informa de la que está incorporada a la corona; tampoco se hace mención de posibles crisis pasadas y los remedios para superarlas. ${ }^{33}$ Asimismo, no hay una relación exhaustiva de acontecimientos coetáneos, ni se proponen remedios a la situación crítica que estaba viviendo el archipiélago por culpa de la suspensión del viaje del galeón a causa de la guerra. El autor no se muestra ni optimista ni pesimista — ¿será porque vive en una región pobre y particularmente abandonada?-; no hay reflexiones profundas sobre las instituciones, el comercio, la población; nada sobre cuestiones tan interesantes como la propiedad o los fenómenos monetarios. Incluso en su disertación sobre el origen de los indios, no nos dice nada de los contactos de la "república de los indios" con la de los "españoles". No hay, pues, una crítica constructiva, no se señalan defectos ni se proponen remedios para subsanarlos. Por ejemplo, en el tema tan importante de lo que ingresan las diversas provincias en las cajas de Manila no se proponen remedios para aquéllas cuya contribución es negativa.

Todo esto nos lleva a pensar que, si efectivamente esta descripción respondiera a un encargo gubernamental, el autor no supo ofrecer lo que de él se esperaba, seguramente porque su mentalidad estaba anclada en el pasado; de ahí que, en lugar de dar respuestas al estado de cosas imperante, se limitase a copiar lo que otros - en este caso fray Juan Francisco de San Antonio- ya habían escrito con otra finalidad. Sin embargo, y a pesar de estas deficiencias, sí es factible pensar que esta relación, tenga o no su origen en la mencionada cédula de 1741, responde a la finalidad de la política borbónica de diferenciar las distintas regiones del imperio con el fin de aplicar en ellas una política de fomento apropiada. Como sabemos, en la segunda mitad del siglo XVIII las autoridades coloniales impulsaron el desarrollo de la riqueza del país. Por ejemplo, en el campo minero se hicieron esfuerzos

33 De este último tenor es, en cambio, el informe de don Simón de Anda y Salazar, oidor de la Audiencia de Filipinas, redactado en Manila el 7 de julio de 1768 (AGI, Filipinas 940). Con el fin de revalorizar las islas después de su toma por los ingleses en 1762, Anda analiza y describe los problemas más puntuales del archipiélago, dejando constancia de todas aquellas circunstancias que habían contribuido a la secular decadencia de la colonia. Dicho informe es estudiado por Cosano Moyano, José: Una visión de Filipinas en el reinado de Carlos III, Córdoba, 1990. (Discursos; 3). 
en el terreno de la prospección y la explotación de yacimientos de oro, hierro y cobre; y en el agrícola se fomentó la extensión y el desarrollo de ciertos cultivos destinados a la exportación: canela, clavo, vainilla, seda... Es verdad que, en gran medida, la ilusión de hacer grandes riquezas se vio frustrada. Pero, como nos dice García de los Arcos ${ }^{34}$ las tentativas continuaron a finales del siglo XVIII, cuando la política económica se encaminó resueltamente a hacer que la colonia pudiera prescindir del situado:

a) Se desarrollaron cultivos como la caña de azúcar, el tabaco y el añil, que estaban destinados a convertirse más tarde en importantes productos de exportación.

b) En cuanto al tabaco, explotado sobre todo en la provincia de Cagayán, en 1782 el gobernador Basco y Vargas implantó su monopolio; e inmediatamente produjo tales ingresos al Estado que la colonia fue en lo sucesivo autosuficiente. El añil también fue cultivado en algunas regiones y exportado por los chinos en su mayor parte.

c) En cuanto a la industria, la más importante era la de los astilleros. Principalmente se encontraban en Cavite; en 1794 se crearon unos en Binondo, arrabal de Manila, para construir embarcaciones dedicadas a la guerra contra los musulmanes. En 1796 el gobierno de Madrid ordenó el traslado de los astilleros de San Blas a Cavite, para reforzar la lucha contra europeos o musulmanes.

d) En cuanto al comercio, hacia 1765 se estableció la comunicación directa España-Filipinas, aunque chocó con la oposición de los interesados en la pervivencia del antiguo galeón transpacífico. En 1769 se creaba en Manila un consulado de comercio y en 1785 el puerto de Manila obtuvo la libertad de comerciar con los países de Asia, extendiéndose a todos los países europeos cuatro años más tarde. Finalmente, la creación de la Compañía de Filipinas coadyuvó al desarrollo de la economía filipina, principalmente en lo que se refiere a la agricultura de exportación: algodón, añil, azúcar, etc., así como el comercio interno, concediendo préstamos a los agricultores.

Todo lo expuesto es señal — según la autora citada - de que en las últimas décadas del siglo XVIII Filipinas comenzó a dar síntomas de actividad en lo que se refiere a las ideas de progreso que defendían los ilustrados de la época. Esto implicó el que las islas comenzaran a desvincularse de la Nueva España en tres aspectos: comenzó a generar rentas propias que

34 García de los Arcos, María Fernanda: Estado y clero en las Filipinas del siglo XVIII, México, 1988, págs. 33-40. 
la liberaron del situado novohispano; diversificó las relaciones comerciales con países europeos y asiáticos; y rompió, al establecerse la comunicación España-Filipinas por el cabo de Buena Esperanza, los lazos con los mercaderes novohispanos que se lucraban con el tráfico del galeón. Así que cuando México se independizó, las Filipinas pudieron seguir unidas a España casi un siglo más.

Por todo lo hasta aquí expuesto y — como ya nos preguntamos- si fuese cierto que esta descripción fue solicitada por la metrópoli con la finalidad ilustrada de conocer para impulsar el desarrollo, podríamos concluir que nos hallamos ante una corografía dieciochesca fallida. En efecto: su contenido demuestra que su autor no supo estar a la altura de las circunstancias, redactando un escrito anclado en la mentalidad de los siglos anteriores, en donde primaba el panegírico y la utopía. El fin de las obras redactadas bajo esta óptica era transmitir una imagen del territorio descrito como poseedor de una posición central y privilegiada en el imperio español. Esta imagen de un territorio o ciudad como centro es un reflejo de la posición que, en su tiempo, asumió Roma. Si nos fijamos en la descripción que presentamos - así como en sus antecesoras- podemos decir que estamos ante la imagen de Filipinas como reencarnación de una nueva Roma. ${ }^{35}$

El modelo de este tipo de descripciones quedó fijado a mediados del siglo XVI y, según Quesada Casajuana, ${ }^{36}$ gira en torno a tres presupuestos: la grandeza, el ánima y la fertilidad del territorio descrito. La "grandeza" significa la consideración del territorio en cuanto a su cantidad y cualidad, lo que tiene que ver con el número de sus ciudadanos y la variedad las instituciones públicas; para demostrar la "grandeza" de un territorio, el autor ha de describir los elementos seculares y religiosos que lo hacen ser un lugar feliz. El "ánima" estaría representada, en primer lugar, por los hombres ilustres que habitan o han habitado el territorio descrito; y en segundo lugar, por la configuración de una sociedad cristiana basada tanto en sus eclesiásticos ilustres como en la presentación de una ciudad que se enorgullece de sus obras de caridad (hospitales, atención al pobre), y que es además defensora y difusora de la fe. Y finalmente, la "fertilidad" queda concretada en tres aspectos: la existencia de un entorno amplio - del que

35 La idea de Roma como modelo de república en la historiografía indiana ha sido estudiado por González Rodríguez, Jaime: La idea de Roma en la historiografía indiana (1492-1550), Madrid, 1981.

36 Quesada Casajuana, Santiago: Las historias de ciudades: geografía, utopía y conocimiento histórico en la Edad Moderna, Barcelona, 1988, especialmente págs. 51-52. Del mismo autor: La idea de ciudad en la cultura hispana de la Edad Moderna, Barcelona, 1992. 
se destacan sus cualidades- que permita el autoabastecimiento; la inclusión de la ciudad en una región climática adecuada dada por una latitud idónea; y la presencia de aires y aguas saludables.

Pues bien, la descripción que presentamos creemos que responde al modelo expuesto, ya que destaca la grandeza, el ánima y la fertilidad de las islas. La "grandeza" queda expuesta al describir sus instituciones políticas (gobernador, Audiencia, comercio, fortalezas y pertrechos militares) y religiosas (enumeración de iglesias, conventos, curatos, hospitales, colegios). Estas últimas reafirman el papel de las islas como centro caritativo y difusor de la fe. Se ofrece así una visión de las Filipinas como unas islas creyentes y evangelizadoras, simbolizadoras del triunfo del cristianismo sobre la herejía. Son, pues, unos territorios providenciales, pues representan una manifestación de los designios divinos.

El "ánima" se encuentra más difusa en esta descripción, aunque puede descubrirse en el relato de las dignidades diocesanas y en la multitud de curatos esparcidos por todas las islas, lo cual las configura como un centro defensor y difusor de la fe. Y por último, la presente descripción — como todas las anteriores que le precedieron- destaca en su primera parte la "fertilidad" de aquéllas, basada en su salubridad, buen clima y vientos favorables. Como vemos, permanece en los escritos del siglo XVIII la ligazón clásica entre fenómenos atmosféricos (aires, temperaturas) y riqueza y carácter del territorio.

Es cierto que grandeza, ánima y fertilidad configuran una imagen de las Filipinas como polis ideal, incluso como un territorio vital del imperio hispano. Pero no era esto precisamente lo que los ilustrados dieciochescos solicitaban. 



\section{Apéndice}

\section{DATOS BIOGRÁFICOS DE JOAQUÍN TRAGGIA}

Joaquín Traggia nació en Zaragoza el 10 de febrero de 1748. Ingresó en la orden de las Escuelas Pías. Su hermano de orden y recién nombrado arzobispo de Manila don Basilio Sancho lo llevó consigo a Filipinas en 1767 y allí, en la Real Pontificia Universidad de Manila, se doctora en teología. Aparte de su labor apostólica, en 1771 publica el Arte de la lengua castellana en la lengua tagalo, con el fin de facilitar a los indios el aprendizaje de la primera. Sirvió de secretario en el concilio provincial celebrado ese mismo año, comisionándosele con plenos poderes para las cortes de Madrid y Roma. Al año siguiente regresa a España y, desembarazado de dicha comisión, se dedicó a la docencia escolapia en Valencia, Zaragoza y Madrid. Abandona la orden, dedicándose desde entonces al estudio. Recompensa de ello es su nombramiento como académico en 1791, desempeñando los cargos de anticuario y bibliotecario desde 1798 hasta su fallecimiento en Madrid en 1802.

Para su biografía contamos con dos obras fundamentales: la semblanza escrita por su hermano Manuel Traggia de Santo Tomás, OCD, Nota sobre la vida de mi hermano Joaquín, sacada de la que escrivió y está en la Academia de la Historia, en Madrid. ${ }^{37} \mathrm{Y}$ el estudio de María Asunción Arija Navarro, La Ilustración aragonesa: Joaquín Traggia (1748-1802), Zaragoza, 1987; en su página 411 aparece citada la presente descripción.

Sucintas referencias pueden consultarse en Félix de Latassa y Ortin, Biblioteca nueva de los escritores aragoneses que florecieron desde el año 1500 hasta 1802, Pamplona, 1798-1802, 6 vols. (tomo VI, págs. 204208). En la obra del marqués de Siete Iglesias, Real Academia de la Historia. Catálogo de sus individuos. Noticias sacadas de su Archivo. I. Académicos de Número, Madrid, 1981 (pág. 72). En el Diccionario de Historia Eclesiástica de España, dirigido por Quintín Aldea Vaquero, Tomás Marín Martínez y José Vives Gatell, Madrid, 1975. Y en la Enciclopedia Universal Ilustrada Europeo-Americana, Madrid, 1928 (tomo 63).

37 No se encuentra ahí sino en la Biblioteca General i Històrica de la Universitat de València, sección Manuscritos, 785-4; 28 ff. 
De entre sus hermanos hay varios escritores, todos ellos citados por Latassa: Felipe, José Joaquín y Domingo Mariano, marqués del Palacio, los tres militares de profesión; y el ya citado Manuel, religioso carmelita. Sobre este último puede consultarse el estudio de Alberto Pacho Polvorinos, Del Antiguo Régimen a la España Moderna. Manuel Traggia (de S. Tomás), OCD, protagonista e intérprete del tránsito, Burgos, 1979.

El catálogo de las obras del padre Joaquín Traggia de Santo Domingo puede encontrarse en Latassa y Ortin, Biblioteca nueva... (tomo VI, páginas 204-208); en Bibliotecas antigua y nueva de escritores aragoneses de Latassa. Aumentadas y refundidas en forma de Diccionario BibliográficoBiográfico por D. Miguel Gómez Uriel, oficial del Archivo y Biblioteca del Ilustre Colegio de Abogados de Zaragoza, Zaragoza, 1884-1886. 3 vols. (tomo III, págs. 273-275); y en José de Calasanz Rabaza de la Virgen del Pilar, Historia de las Escuelas Pías de España, Valencia, 1917-1918. 4 vols. (tomo II, pág. 422).

Sobre el abandono de la orden escolapia, el citado Rabaza nos dice que Traggia fue "otro de los soldados de Gedeón que se abocaron al torrente; pero no fue la atracción mundana la que le arrastró; fue su carácter acedo y rijoso lo que le despegó de sus Hermanos y Madre; dejó de ser Escolapio por molesta cohabitación. Creo que siguió siendo Escolapio y sólo cambió la residencia con autorización pontificia”. 